1996

\title{
Seasonal variability of particulate organic radiocarbon in the northeast Pacific ocean
}

\author{
Ellen R.M. Druffel \\ University of California, Irvine \\ James E. Bauer \\ Virginia Institute of Marine Science \\ Peter M. Williams \\ Scripps Institution of Oceanography \\ Shelia Griffin \\ University of California, Irvine \\ David Wolgast \\ Scripps Institution of Oceanography
}

Follow this and additional works at: https://scholarworks.wm.edu/vimsarticles

Part of the Marine Biology Commons

\section{Recommended Citation}

Druffel, Ellen R.M.; Bauer, James E.; Williams, Peter M.; Griffin, Shelia; and Wolgast, David, Seasonal variability of particulate organic radiocarbon in the northeast Pacific ocean (1996). JOURNAL OF GEOPHYSICAL RESEARCH-OCEANS, 101, 20543-20552.

10.1029/96JC01850

This Article is brought to you for free and open access by the Virginia Institute of Marine Science at W\&M ScholarWorks. It has been accepted for inclusion in VIMS Articles by an authorized administrator of W\&M ScholarWorks. For more information, please contact scholarworks@wm.edu. 


\title{
Seasonal variability of particulate organic radiocarbon in the northeast Pacific Ocean
}

\author{
Ellen R. M. Druffel, ${ }^{1}$ James E. Bauer, ${ }^{2}$ Peter M. Williams, ${ }^{3}$ \\ Sheila Griffin, ${ }^{1}$ and David Wolgast ${ }^{3}$
}

\begin{abstract}
We present $\Delta^{14} \mathrm{C}$ measurements of particulate organic carbon (POC) collected on four cruises at our time series site (station $M$ ) in the northeast Pacific Ocean. We observe a large gradient with depth in the suspended POC $\Delta^{14} \mathrm{C}$ values $(124-160 \%$ ). These profiles display lower $\Delta^{14} \mathrm{C}$ values (by $20-30 \%$ ) in samples between $2500 \mathrm{~m}$ and the bottom during June 1992 and July 1993 than those during February and October 1992. Values of $\Delta^{14} \mathrm{C}$ in sinking POC from deep-moored sediment trap collections suggest a semiannual trend that displays lower overall $\Delta^{14} \mathrm{C}$ in material collected during periods of high flux. A limited number of $\Delta^{14} \mathrm{C}$ measurements of small swimmers picked from the trap $650 \mathrm{~m}$ above bottom are similar to surface $\Delta^{14} \mathrm{C}$ measurements of dissolved inorganic carbon (DIC) and suspended POC, indicating a surface carbon source. Overall, we postulate that the major process causing lower $\Delta^{14} \mathrm{C}$ values of deep suspended and sinking POC is sorption (or biological incorporation) of "old" DOC onto particulate matter.

There appears to be a higher ratio of DOC sorbed to sinking particulate matter at times of high flux (late spring and early fall) that can be thought of as a "stripping out" of DOC from the water column. The DIC $\Delta^{14} \mathrm{C}$ display a small seasonal variation in the surface waters and is not the sole source of the observed seasonality in the POC $\Delta^{14} \mathrm{C}$ signals.
\end{abstract}

\section{Introduction}

A major reason the oceanic carbon cycle is an important study area is its connection, via gas exchange, with the atmospheric greenhouse gas $\mathrm{CO}_{2}$. The residence time of ${ }^{14} \mathrm{CO}_{2}$ in the atmosphere with respect to exchange with the oceans is about 10 years, relatively rapid compared to the $e$-folding time for fossil fuel $\mathrm{CO}_{2}$ [Broecker et al., 1960; Druffel and Linick, 1978]. Following its diffusion across the air-sea interface, $\mathrm{CO}_{2}$ is hydrated and mixed into the upper layer of the water column as dissolved inorganic carbon (DIC). The DIC is fixed by photosynthesis in the euphotic zone to particulate organic carbon (POC), and a portion of the POC falls through the water column $\left(\mathrm{POC}_{\text {sink }}\right)$. A large portion of this $\mathrm{POC}_{\mathrm{sink}}$ is remineralized by marine organisms including bacteria or otherwise transformed into smaller particles that remain suspended $\left(\mathrm{POC}_{\text {susp }}\right)$ in the water column for variable periods of time. These two particle fractions act as a short circuit between the surface and deep ocean carbon pools. This short circuit connection is the subject of this paper.

One of the major questions we address is, How fast does POC that is produced in the surface waters of the ocean transit the water column en route to the deep sea, and how is it altered during its transit? Stable carbon isotope ratios of foraminiferal tests falling into a deep trap in the North Atlantic have been shown to be reliable recorders of near-surface properties 1

\footnotetext{
${ }^{1}$ Department of Earth System Science, University of California, Irvine.

${ }^{2}$ School of Marine Sciences, College of William and Mary, Gloucester Point, Virginia.

${ }^{3}$ Scripps Institution of Oceanography, University of California, San Diego, La Jolla.

Copyright 1996 by the American Geophysical Union.

Paper number $96 \mathrm{JC} 01850$.

0148-0227/96/96JC-01850\$09.00
}

month prior to their arrival in the trap [Deuser, 1986]. Thorium isotope results were used to show that the turnover time of suspended matter in the deep tropical Pacific was of the order of 5 to 10 years [Bacon and Anderson, 1982]. This is irrespective of the fact that reaction times are short (a few months), indicating that the surfaces of suspended particles in the deep sea are close to equilibrium, at least with respect to the exchange of metals.

Measurements of bomb-produced ${ }^{14} \mathrm{C}$ in $\mathrm{POC}_{\text {susp }}$ in the North Pacific [Druffel and Williams, 1990] and North Atlantic [Druffel et al., 1992] during the late 1980s revealed large gradients of $\Delta^{14} \mathrm{C}$ with depth (Figure 1). The bomb radiocarbon signal of DIC reached a maximum in the temperate surface oceans in the early 1970s [Druffel and Linick, 1978; Druffel, 1987]. Thus one would not expect a gradient with depth in $\mathrm{POC}_{\text {susp }} \Delta^{14} \mathrm{C}$ values in the late 1980 s, assuming that POC turns over quickly ( $\leq 10$ years) and vertical fluxes, originating from the surface water, dominate the POC input to the deep ocean. However, it appeared that old carbon was transported to the deep sea via $P O C_{\text {susp }}$ (and to a lesser extent via $P O C_{\text {sink }}$ ) transiting through the water column.

The impetus for this study was to evaluate, on a seasonal basis, the role of POC in the transport of old carbon to the deep sea. While previous measurements of $\Delta^{14} \mathrm{C}$ in $\mathrm{POC}_{\text {susp }}$ and $\mathrm{POC}_{\text {sink }}$ from the oligotrophic North Pacific and North Atlantic Oceans [Druffel and Williams, 1990; Druffel et al., 1992] were made during single cruises, they revealed no information about the seasonal variability of $\Delta^{14} \mathrm{C}$. Hence we chose to examine an area of the ocean where surface primary productivity and near-bottom fluxes of $\mathrm{POC}_{\text {sink }}$ varied severalfold on a seasonal basis. This provided an opportunity to study a natural system in which these factors regulated time- and depthdependent changes in $\Delta^{14} \mathrm{C}$ of POC.

This study was part of a larger project that included the study of carbon isotopes $\left({ }^{14} \mathrm{C},{ }^{13} \mathrm{C}\right)$ and concentrations of dis- 


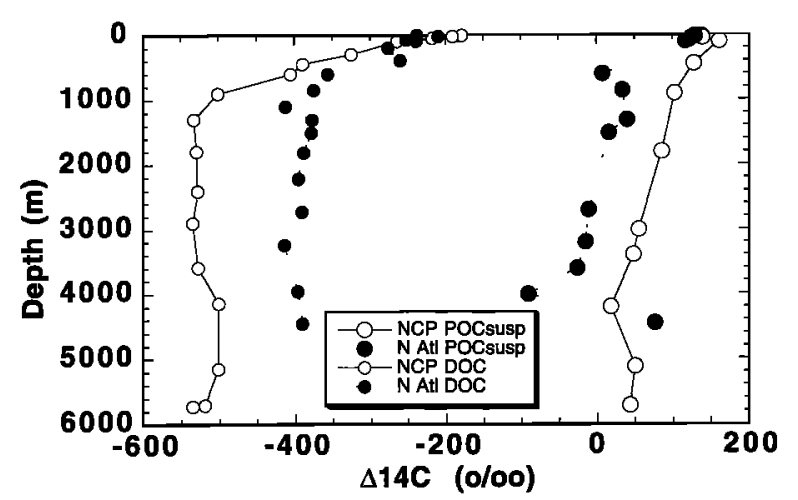

Figure 1. Comparison of the $\Delta^{14} \mathrm{C}$ measurements for $\mathrm{DOC}_{\mathrm{UV}}$ and $\mathrm{POC}_{\text {susp }}$ from the North Atlantic $\left(32^{\circ} \mathrm{N}, 64^{\circ} \mathrm{W}\right)$ in June-July 1989 and the north central Pacific $\left(31^{\circ} \mathrm{N}, 159^{\circ} \mathrm{W}\right)$ in June-July 1987 [after Druffel et al., 1992].

solved organic carbon (DOC) in the same set of water samples collected for the DIC $\Delta^{14} \mathrm{C}$ analyses discussed here. Suspended and sinking POC samples were also collected during the same cruises. Results of the DOC and DIC concentrations and $\Delta^{14} \mathrm{C}$ measurements are published elsewhere (J. Bauer et al., Interand intra-annual variability in isotopic $\left({ }^{14} \mathrm{C}\right.$ and $\left.{ }^{13} \mathrm{C}\right)$ signatures of dissolved organic carbon in the eastern North Pacific Ocean, submitted to Journal of Geophysical Research, 1995, hereinafter referred to as BDWWG; E. R. M. Druffel and C. Masiello, manuscript in preparation, 1996). It is important to remember that the difference between POC and DOC is based purely on a size-dependent, operational definition. DOC is the organic carbon that passes a $1-\mu \mathrm{m}$ filter, and POC is that which is collected by it. It may be appropriate to think of DOC and POC as being similar in a number of respects [Vernonclark et al., 1995], such as their chemical, physical, and isotopic properties. One example of where this may be true is for small POC (1-10 $\mu \mathrm{m})$ and large DOC $(10,000$ daltons to $1 \mu \mathrm{m})$.

It is also important to note here that the carbon isotopic signatures reported here for POC and DOC samples are of bulk analyses that represent averages of the individual molecular components of each sample. Thus generalizations based on the bulk average isotopic values are all that can be quantified now, until new techniques designed to date individual organic compounds are widely applied to geochemical samples [cf. Eglinton et al., 1996].

\section{Sampling Site}

Our area of study was a single site (station $\mathrm{M}, 34^{\circ} 50^{\prime} \mathrm{N}$, $123^{\circ} 00^{\prime} \mathrm{W}$, depth $\sim 4100 \mathrm{~m}$ ) located $220 \mathrm{~km}$ west of Point Conception, California, in the northeast Pacific Ocean. Sediments are composed of red clay, and the seafloor has low relief. The southward flowing California Current exerts a dominant influence on the sea surface in this region, and there are spring plumes of chlorophyll [Michaelsen et al., 1988; Smith et al., 1988] [Peláez and McGowan, 1986] that vary on an interannual basis.

Two maxima per year are usually observed in the flux of particulate organic material to the deep sea at station $M$, the primary one in late spring and the secondary one in early fall [Smith et al., 1994]. The flux values at $600 \mathrm{~m}$ above bottom (mab) range from a low of $1-3 \mathrm{mg} \mathrm{C} \mathrm{m}^{-2} \mathrm{~d}^{-1}$ in winter and early spring to a high of $10-25 \mathrm{mg} \mathrm{C} \mathrm{m}^{-2} \mathrm{~d}^{-1}$ during and immediately after the major late spring bloom [Smith et al., 1994]. Fluxes during late spring of 1992 were lower than normal (5-7 $\mathrm{mg} \mathrm{m}^{-2} \mathrm{~d}^{-1}$ ) and are attributed to the El NiñoSouthern Oscillation (ENSO) event that peaked during this year (K. L. Smith, personal communication, 1995).

We report data from samples collected during four cruises to station M: Pulse 11 (February 19 to March 2, 1992), Pulse 12 (June 19 to July 1, 1992), Pulse 15 (October 15-27, 1992), and Pulse 17 (July 14-23, 1993). These cruises were part of a separate program that emphasized the study of the coupling between near-bottom pelagic POC fluxes and benthic processes [Smith et al., 1994].

\section{Methods}

Suspended POC was collected using in situ Yentsch pumps [Druffel et al., 1992; Williams et al., 1980] deployed for 2-8 hours at 8-10 depths during February, June, and October 1992 and July 1993. During each deployment, 600-2500 L of seawater were filtered through $0.8-\mu \mathrm{m}$ pore diameter, precombusted $\left(550^{\circ} \mathrm{C}\right)$ quartz fiber filters (Whatman ultrapure QM-A, $145 \mathrm{~mm}$ diameter). The filters were then frozen at $-20^{\circ} \mathrm{C}$ in glass jars in the dark.

Sediment traps were used to collect sinking POC at 650,600 , 100 , and $50 \mathrm{mab}$. The traps were Teflon-coated fiberglass cones (120 cm long, $57 \mathrm{~cm}$ diameter) with a mouth opening of 0.25 $\mathrm{m}^{2}$ [Bruland et al., 1981]. Collections were taken for 10-30 days at each depth, with mercuric chloride used in all trap deployments as a poison. There were numerous breaks in the sampling sequences owing to inadequate availability of material. The reader is referred to a separate publication for further details of the sediment trap program for samples collected at 50 and 600 mab [Smith et al., 1994]. Sinking POC was concentrated by gentle vacuum filtration of approximately $0.7 \mathrm{~L}$ trap liquid onto precombusted, quartz fiber filters (45 mm diameter, $0.8 \mu \mathrm{m}$ pore diameter).

The filters containing the suspended POC were acidified to $p \mathrm{H}<2$ with $1 \% \mathrm{H}_{3} \mathrm{PO}_{4}$ for 24 hours to remove the carbonates, dried under vacuum, and combusted at $850^{\circ} \mathrm{C}$ for 1 hour in double quartz tubes with $\mathrm{CuO}$ and silver according to standard techniques [Druffel et al., 1992]. Aliquots of the sinking POC samples were acidified with $1 \% \mathrm{H}_{3} \mathrm{PO}_{4}$ and dried at $50^{\circ} \mathrm{C}$ before combustion as above.

Seawater DIC samples were filtered through a precombusted $\left(550^{\circ} \mathrm{C}\right), 147-\mathrm{mm}$-diameter, glass fiber filter (Gelman type A/E glass) from $12-\mathrm{L}$ or $30-\mathrm{L}$ Go-Flo sampling bottles. The sample $(0.5 \mathrm{~L})$ was poisoned with $100 \mu \mathrm{L}$ of saturated $\mathrm{HgCl}_{2}$ solution, sealed, and stored at room temperature. DIC was extracted from 0.25 -L subsamples after acidification with concentrated $\mathrm{H}_{3} \mathrm{PO}_{4}$ according to standard techniques [ $\mathrm{McNi}$ chol et al., 1994].

The $\mathrm{CO}_{2}$ from POC and DIC was converted to graphite targets [Vogel et al., 1987] either at Lawrence Livermore National Laboratory (LLNL) or at the University of California, Irvine (UCI), and ${ }^{14} \mathrm{C}$ was measured using accelerator mass spectrometry (AMS) at the Center for AMS Research at LLNL. A few of the samples were converted to graphite and analyzed for ${ }^{14} \mathrm{C}$ at the National Ocean Sciences AMS Facility at the Woods Hole Oceanographic Institution (WHOI). Radiocarbon measurements are reported as $\Delta^{14} \mathrm{C}$ (per mil) [Stuiver and Polach, 1977]. Total errors (laboratory plus statistical) for the individual AMS $\Delta^{14} \mathrm{C}$ measurements range in general from \pm 5 to $\pm 9 \%$. $\Delta^{14} \mathrm{C}$ values are corrected for blank 
$\mathrm{CO}_{2}$ added during combustion (POC) and acidification (DIC) as well as that added during the production of graphite. Combustion blanks were larger and comprised $0.2 \%$ to $8.0 \%$ of the sample $\mathrm{CO}_{2}$ volumes; they had an average $\Delta^{14} \mathrm{C}$ value of $-800 \pm 50 \%$ for double-tube combustions. Stable carbon isotope results $\left(\delta^{13} \mathrm{C}\right)$ for samples in this study were performed on splits of $\mathrm{CO}_{2}$ from the double-tube combustion step (POC) or the acidification step (DIC). The $\delta^{13} \mathrm{C}$ measurements were made on the VG Micromass $602 \mathrm{E}$ isotope ratio mass spectrometer and had an overall error of $\pm 0.10 \%$.

\section{Results}

DIC

Knowledge of the $\Delta^{14} \mathrm{C}$ signature of DIC in surface seawater is important for interpreting the $\Delta^{14} \mathrm{C}$ of $\mathrm{POC}$, because during photosynthesis the phytoplankton draw from the DIC pool to produce organic matter. Theoretically, the $\Delta^{14} \mathrm{C}$ of organic matter produced during photosynthesis should equal that in the DIC of the surrounding surface seawater [Williams and Linick, 1975]. Results of $\Delta^{14} \mathrm{C}$ of DIC measurements made in samples from four cruises are shown in Figures $2 \mathrm{a}$ and $2 \mathrm{~b}$. These data and that from several other cruises to station $M$ are described fully in a separate publication (E. R. M. Druffel and C. Masiello, manuscript in preparation, 1996).

The $\Delta^{14} \mathrm{C}$ results were highest in surface waters, and ranged from $72 \%$ (June 1992) to 58\%o (July 1993) at $25 \mathrm{~m}$ depth. The lowest $\Delta^{14} \mathrm{C}$ values were found between $1600 \mathrm{~m}$ and $3500 \mathrm{~m}$ and ranged from $-233 \%$ to $-247 \%$. Intercruise comparisons of $\Delta^{14} \mathrm{C}$ values measured at a given depth showed the most variability above $800 \mathrm{~m}$ (54\%o range observed at $450 \mathrm{~m}, N=$
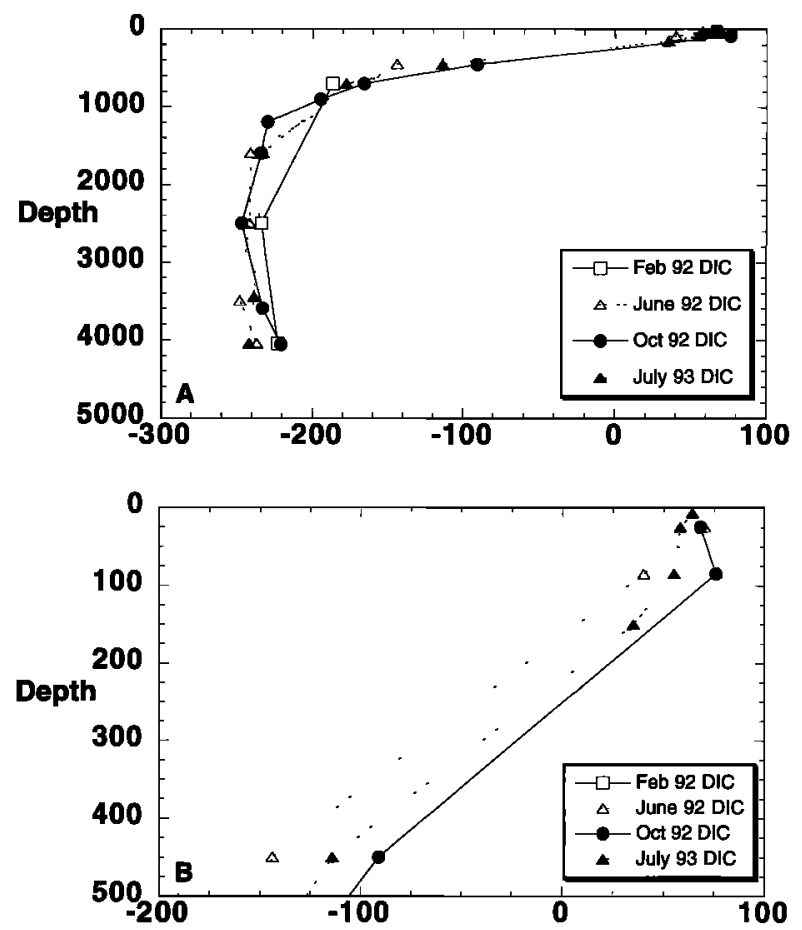

Figure 2. $\Delta^{14} \mathrm{C}$ of DIC samples collected using Go-Flo bottles at depths of (a) 0-5000 m and (b) 0-1000 m during four cruises from February 1992 to June 1993 . Only three analyses are available from Pulse 11 (February 1992), since most of the samples were lost during processing.
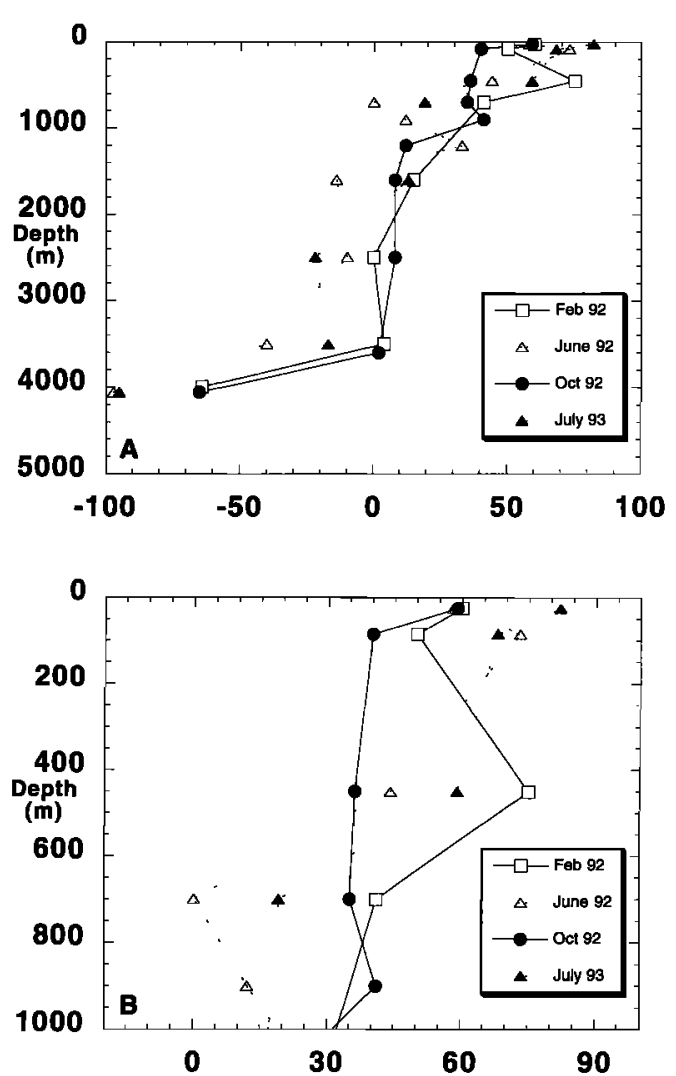

Figure 3. Comparison of the $\Delta^{14} \mathrm{C}$ measurements for $\mathrm{POC}_{\text {susp }}$ at station $M$ during four time periods in 1992 and 1993 at depths of (a) $0-4050 \mathrm{~m}$ and (b) $0-1000 \mathrm{~m}$. Points are February 1992 (open squares), June 1992 (open triangles), October 1992 (solid circles), and July 1993 (solid triangles). Averages of duplicate $\Delta^{14} \mathrm{C}$ values are plotted.

3 ); at $4060 \mathrm{~m}$ depth, the range (21\%o range, $N=4$ ) was less than half that at $450 \mathrm{~m} . \Delta^{14} \mathrm{C}$ measurements for samples from depths between 800 and $3500 \mathrm{~m}$ varied by no more than the $2 \sigma$ error $(\sim 14 \%)$. It is interesting to note that the two lowest DIC $\Delta^{14} \mathrm{C}$ results at $50 \mathrm{mab}$ (4060 m depth) were from late spring to early summer (June 1992 and July 1993).

In surface waters $(25-85 \mathrm{~m}), \Delta^{14} \mathrm{C}$ values for $\mathrm{DIC}$ were available from three time periods, June and October 1992 and July 1993 (Figure 2b). Values were high during October 1992 at both $25 \mathrm{~m} \mathrm{(68 \% o)} \mathrm{and} 85 \mathrm{~m}(76 \% 0)$ and somewhat lower at the three shallowest surface depths during July 1993 (64\%o at $7 \mathrm{~m}, 58 \%$ at $25 \mathrm{~m}$, and $55 \%$ at $85 \mathrm{~m}$ ). There was a gradient of $30 \%$ between 25 and $85 \mathrm{~m}$ in the June 1992 data $\left(\Delta^{14} \mathrm{C}_{25 \mathrm{~m}}\right.$ minus $\Delta^{14} \mathrm{C}_{85 \mathrm{~m}}=72 \%-42 \%$ ). Upwelling normally occurs at this site during the summer, causing ${ }^{14} \mathrm{C}$-depleted subsurface waters to invade the surface water, accounting for the low values during June 1993. However, the ENSO conditions during 1992 inhibited upwelling during this time, resulting in a stratified water column with a high DIC $\Delta^{14} \mathrm{C}$ value in the warm near-surface waters. From these limited data the seasonal variability of the surface $(\leq 25 \mathrm{~m})$ DIC $\Delta^{14} \mathrm{C}$ signature appeared to have been at least $14 \%$ (E. R. M. Druffel and C. Masiello, manuscript in preparation, 1996).

\section{Suspended POC}

The suspended POC ( $\mathrm{POC}_{\text {susp }}$ ) $\Delta^{14} \mathrm{C}$ profiles for the four sampling periods (Figure 3 and Table 1 ) decreased markedly 
Table 1. Measurements of $\Delta^{14} \mathrm{C}$ and $\delta^{13} \mathrm{C}$ for Suspended Particulate Organic Carbon During Four Cruises to Station $\mathrm{M}$ in the Northeast Pacific

\begin{tabular}{|c|c|c|c|c|c|c|}
\hline \multirow{2}{*}{$\begin{array}{l}\text { Depth, } \\
\text { m }\end{array}$} & \multicolumn{3}{|c|}{ Number } & \multirow{2}{*}{$\underset{\% O 0}{\mathrm{POC}_{\text {susp }} \Delta^{14} \mathrm{C}}$} & \multirow{2}{*}{$\begin{array}{c}\delta^{13} \mathrm{C} \\
\% o\end{array}$} & \multirow{2}{*}{$\begin{array}{l}{[\mathrm{POC}],} \\
\mu \mathrm{g} \mathrm{L}^{-1}\end{array}$} \\
\hline & UCID & OSG & CAMS & & & \\
\hline \multicolumn{7}{|c|}{ Pulse 11 (February 1992) } \\
\hline 25 & 280 & 1354 & 5082 & $51 \pm 6,81 \pm 12$ & -22.40 & 74.50 \\
\hline 85 & 281 & 1355 & 5602 & $45 \pm 7,56 \pm 7$ & -22.69 & 12.50 \\
\hline 450 & 334 & & 5604 & $75 \pm 10$ & -21.64 & 2.80 \\
\hline 700 & 283 & 1356 & & $41 \pm 6$ & -21.73 & 1.15 \\
\hline 1600 & 288 & 1360 & & $15 \pm 6$ & -21.56 & 1.74 \\
\hline 2500 & 286,287 & 1358,1359 & & $7 \pm 9,-4 \pm 6$ & -21.65 & 1.32 \\
\hline 3500 & 333 & & 5603 & $4 \pm 7$ & -21.25 & 1.42 \\
\hline 4000 & 284 & 1357 & & $-64 \pm 5$ & -20.86 & 2.08 \\
\hline \multicolumn{7}{|c|}{ Pulse 12 (June 1992) } \\
\hline 25 & 339 & & 5607 & $58 \pm 7$ & -22.91 & 38.70 \\
\hline 85 & 341 & & 5608 & $73 \pm 8$ & -23.75 & 19.60 \\
\hline 450 & 335 & & 4900 & $44 \pm 7$ & -21.74 & 4.04 \\
\hline 700 & 337 & & 5605,5083 & $7 \pm 7,-13 \pm 11$ & -21.19 & 3.19 \\
\hline 900 & 450 & & N6473 & $12 \pm 12$ & -21.08 & 2.99 \\
\hline 1200 & 449 & & $\mathrm{~N} 6472$ & $33 \pm 7$ & -21.05 & 2.38 \\
\hline 1600 & 419 & & N6073 & $-14 \pm 6$ & -20.53 & 3.19 \\
\hline 2500 & 336 & & 4901 & $-10 \pm 6$ & -21.46 & 1.81 \\
\hline 3500 & 338 & & 5606 & $-40 \pm 7$ & -21.20 & 1.63 \\
\hline 4060 & 418 & & N6071 & $-97 \pm 6$ & -20.46 & 5.63 \\
\hline \multicolumn{7}{|c|}{ Pulse 15 (October 1992) } \\
\hline 25 & 427 & & N6078 & $59 \pm 7$ & -21.89 & 78.40 \\
\hline 85 & 421 & & N6453 & $40 \pm 7$ & -22.77 & 26.20 \\
\hline 450 & 420 & & N6074 & $36 \pm 7$ & -20.22 & 7.24 \\
\hline 700 & 423 & & N6076 & $35 \pm 10$ & & 5.40 \\
\hline 900 & 428 & & N6077 & $41 \pm 7$ & $-2 \dot{0} .59$ & 5.48 \\
\hline 1200 & 429 & & N6066 & $12 \pm 7$ & & 5.07 \\
\hline 1600 & 426 & & N6075 & $8 \pm 7$ & -20.60 & 4.40 \\
\hline 2500 & 424 & & N6069 & $8 \pm 6$ & -20.97 & 4.55 \\
\hline 3500 & 425 & & N6068 & $2 \pm 7$ & -20.67 & 2.50 \\
\hline 4060 & 422 & & N6072 & $-65 \pm 7$ & -21.46 & 4.00 \\
\hline \multicolumn{7}{|c|}{ Pulse 17 (July 1993) } \\
\hline 25 & 540 & & & $82 \pm 6$ & -22.73 & 38.33 \\
\hline 85 & 510 & & 17432 & $68 \pm 5$ & -20.02 & 24.02 \\
\hline 450 & 539 & & & $59 \pm 6$ & -21.36 & 4.45 \\
\hline 700 & 452 & & N6475 & $19 \pm 7$ & -20.39 & 4.08 \\
\hline 1600 & 451 & & N6474 & $13 \pm 8$ & -20.23 & 3.04 \\
\hline 2500 & 481 & & 15239 & $-22 \pm 7$ & -21.30 & 1.86 \\
\hline 3510 & 444 & & N6467 & $-17 \pm 6$ & -20.84 & 1.24 \\
\hline 4060 & 482 & & 15242 & $-95 \pm 7$ & -21.10 & 2.48 \\
\hline
\end{tabular}

$\Delta^{14} \mathrm{C}$ is reported as per mil according to convention [Stuiver and Polach, 1977], and $\delta^{13} \mathrm{C}$ are the per mil deviation from PDB 1 standard. Also listed are the AMS target numbers (CAMS for LLNL and OSG for WHOI NOSAMS samples), and UCID $\mathrm{CO}_{2}$ gas numbers associated with each $\mathrm{POC}_{\text {susp }}$ sample. The reported concentrations of $\mathrm{POC}_{\mathrm{su}>\mathrm{p}}$ are calculated using the manometric measure of $\mathrm{CO}_{2}$ obtained from the double-tube combustion of a single quartz filter (see text) and the measured volume of seawater filtered through each quartz filter. Two filters were run for Pulse $112500 \mathrm{~m}$ (UCID 286, 287), and the two $\Delta^{14} \mathrm{C}$ values $\left(7 \pm 9,-4 \pm 6 \%\right.$ ) were within $2 \sigma$ error. Splits of the $\mathrm{CO}_{2}$ run for Pulse $1125 \mathrm{~m}$ and $85 \mathrm{~m}$ (UCID 280 and 281) were analyzed at WHOI (OSG) and LLNL (CAMS) and the $\Delta^{14} \mathrm{C}$ values were within $2.5 \sigma$ error.

with depth. We found no relationship between the volume of seawater filtered and the $\Delta^{14} \mathrm{C}$ of the $\mathrm{POC}_{\mathrm{susp}}$, eliminating the possibility that DOC was being adsorbed onto filters in a cumulative fashion. Values ranged from +58 to $82 \%$ at $25 \mathrm{~m}$ depth, and -64 to $-97 \%$ at $50 \mathrm{mab}(\sim 4060 \mathrm{~m}$ depth). This reflected depth gradients $\left(\Delta^{14} \mathrm{C}_{25 \mathrm{~m}}\right.$ minus $\left.\Delta^{14} \mathrm{C}_{50 \mathrm{mab}}\right)$ in the water column during February, June and October 1992 and July 1993 of $130 \%$, $155 \%, 124 \%$ and $\sim 177 \%$, respectively. The depth gradients were significantly larger (by 25-53\%o) for June 1992 and July 1993 than for the other two sampling periods. Below $1600 \mathrm{~m}$ depth, the $\Delta^{14} \mathrm{C}$ values for $\mathrm{POC}_{\text {susp }}$ from the June 1992 and July 1993 profiles were consistently lower $(20-30 \%$ o) than those for February or October 1992.
Also, $\Delta^{14} \mathrm{C}$ values from $85 \mathrm{~m}$ samples were $20-30 \%$ higher for the June 1992 and July 1993 than for February and October 1992 (Figure 3b). This was in contrast to the DIC $\Delta{ }^{14} \mathrm{C}$ data, where June 1992 and July 1993 values at $85 \mathrm{~m}$ were lower (by 25-35\%o) than that from October 1992.

All of the $\Delta^{14} \mathrm{CPOC}_{\text {susp }}$ profiles exhibited lower values at 50 mab than the trends higher in the water column would have predicted. These lower values indicated that old POC from bottom sediments had been resuspended into the water column.

The subsurface values of $\mathrm{POC}_{\text {susp }}$ concentrations from the four cruises varied by a factor of 3 in the water column on a temporal basis (Figure 4, plotted on a log scale, and Table 1). 


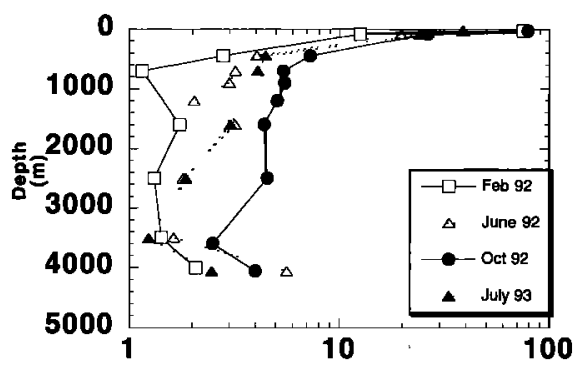

Figure 4. Comparison of $\mathrm{POC}_{\text {susp }}$ concentrations (in micrograms per liter) at station $M$ during four time periods in 1992 and 1993. Note the $\log$ scale used for the $x$ axis. POC concentration values have an error of approximately $\pm 10 \%$. Points are the same as for Figure 3.

Concentrations of $\mathrm{POC}_{\text {susp }}$ were lowest throughout the water column (at all but $25 \mathrm{~m}$ depth) during the month of February 1992 and were highest during October 1992. At the surface (25 $\mathrm{m}), \mathrm{POC}_{\text {susp }}$ concentrations were lower during June 1992 and July 1993 ( 38.7 and $33.3 \mu \mathrm{g} \mathrm{C} \mathrm{L}^{-1}$ ) than either February or October 1992 (74.5 and 78.4 $\mu \mathrm{g} \mathrm{C} \mathrm{L}^{-1}$ ). All profiles showed an increase at the depth nearest the seafloor $(50 \mathrm{mab}$ or $\sim 4050 \mathrm{~m}$ depth) and indicated, along with low $\Delta^{14} \mathrm{C}$ values, resuspension of POC from bottom sediments. This agreed with transmissometer data that showed a significant decrease in light transmission below 200 mab at this site [Smith et al., 1994]. It also agreed with higher suspended mass values at 50 and 100 mab during the June 1992 and November 1993 cruises to station M [Sherrell, 1994; also R. Sherrell, manuscript in preparation, 1996].

Whereas the June 1992 and July 1993 profiles below $1600 \mathrm{~m}$ depth displayed the lowest $\Delta^{14} \mathrm{C}$ values, the corresponding $\mathrm{POC}_{\text {susp }}$ concentrations were intermediate between those in February and October 1992. Nonetheless, the $\mathrm{POC}_{\text {susp }}$ concentrations increased during 1992, from the lowest values in February to the highest values in October. Despite the fact that February and October 1992 displayed extremes in POC $_{\text {susp }}$ concentrations, their $\Delta^{14} \mathrm{C}$ profiles were virtually identical. There was also no direct correlation between the POC concentration profiles and the DOC concentration profiles obtained during these cruises at station $\mathrm{M}$ (BDWWG).

The $\delta^{13} \mathrm{C}$ values for $\mathrm{POC}_{\text {susp }}$ ranged from a low of $-23.8 \%$ o in the chlorophyll maximum ( $85 \mathrm{~m}$ ) during June 1992 to a high

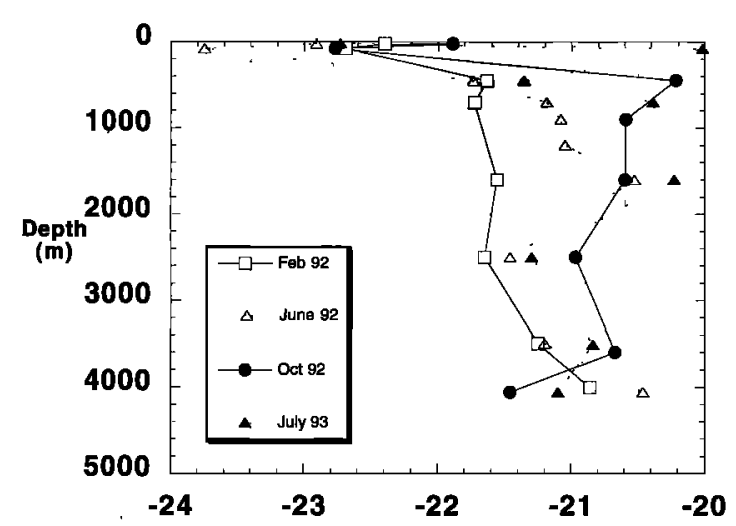

Figure 5. Comparison of the $\delta^{13} \mathrm{C}$ measurements for $\mathrm{POC}_{\text {susp }}$ at station $\mathrm{M}$ during four time periods in 1992 and 1993. Points are the same as for Figure 3.
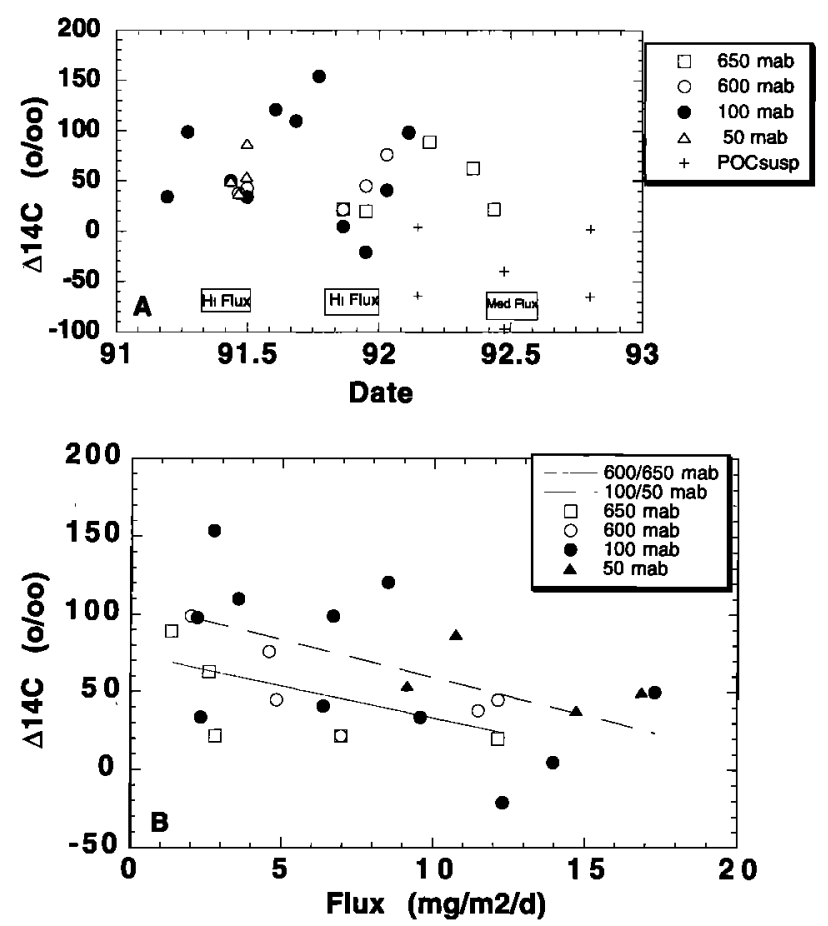

Figure 6. (a) $\Delta^{14} \mathrm{C}$ of $\mathrm{POC}_{\text {smk }}$ collected in sediment traps deployed at station $M$ at four depths $(650,600,100$, and 50 mab; see legend). All samples were collected over a 30-day period, with the exception of the 50-mab samples (10-day period). For comparison, $\Delta^{14} \mathrm{C}$ of $\mathrm{POC}_{\text {susp }}$ samples collected during three time periods at 50 and $650 \mathrm{mab}$ are plotted as pluses. (b) Flux rate (milligrams per square meter per day) versus $\Delta^{14} \mathrm{C}$ of $\mathrm{POC}_{\text {sink }}$ for samples collected in sediment traps from four depths in the deep sea $(650,600,100$, and 50 mab; see legend). The least squares fit of the values from the 650and $600-$ mab traps is indicated by a solid line ( $r=0.59, N=$ 11 , correlation significant to the $90 \%$ level), and that from the 100 - and 50 -mab traps is indicated by a dashed line $(r=$ $0.538, N=15$, correlation significant to the $95 \%$ level).

of $-20.0 \%$ at the same depth in July 1993 (Figure 5). General trends were similar in the four $\delta^{13} \mathrm{C}$ profiles: (1) low values in surface samples (25-85 m, except $85 \mathrm{~m}$ in July 1993), and (2) values in the middepth region had a larger range $(\sim 1.4 \%$ ) than those deeper in the water column. There was also a progression toward higher values with time from February 1992 to July 1993 between the depths of 700 and $1600 \mathrm{~m}$. The highest $\delta^{13} \mathrm{C}$ values were observed in October 1992 and July 1993, when higher flux rates of $P{ } C_{\text {sink }}$ to the deep sea were observed (K. L. Smith, personal communication, 1995). In contrast, the lowest $\delta^{13} \mathrm{C}$ values and the smallest amount of variability of $\delta^{13} \mathrm{C}$ with depth were observed in the profile for February 1992, the period of lowest flux.

\section{Sinking POC}

The $\Delta^{14} \mathrm{C}$ measurements of sinking POC $\left(\mathrm{POC}_{\text {sink }}\right)$ for the 1.5-year time period between February 1991 and June 1992 are shown in Figure 6a. Results are presented for samples that were available from four sampling heights above the seafloor: 650, 600, 100, and 50 mab. Also shown in Figure 6a for comparison are the $\Delta^{14} \mathrm{C}$ values obtained for $\mathrm{POC}_{\text {susp }}$ from 650 and 50 mab during three sampling times in 1992. The sample from 650 mab in April 1992 had been contaminated with tracer 
Table 2. Measurements of $\Delta^{14} \mathrm{C}$ and $\delta^{13} \mathrm{C}$ and Associated Errors for Sinking Particulate Organic Carbon Collected From March 1991 to June 1992 at Station M in the Northeast Pacific

\begin{tabular}{|c|c|c|c|c|c|c|c|}
\hline \multicolumn{2}{|c|}{ Number } & \multirow{2}{*}{$\begin{array}{l}\text { Duration, } \\
\text { days }\end{array}$} & \multirow{2}{*}{$\begin{array}{c}\text { Date } \\
\text { (Midpoint) }\end{array}$} & \multirow{2}{*}{$\begin{array}{l}\text { Event, } \\
\text { Cup Number }\end{array}$} & \multirow{2}{*}{$\underset{\% 0}{\mathrm{POC}_{\text {sink }}} \Delta^{14} \mathrm{C}$} & \multirow{2}{*}{$\begin{array}{l}\text { Organism } \\
\Delta^{14} \mathrm{C}, \% o\end{array}$} & \multirow{2}{*}{$\begin{array}{l}\delta^{13} \mathrm{C} \\
\% 0\end{array}$} \\
\hline UCID & CAMS & & & & & & \\
\hline \multicolumn{8}{|c|}{$650 \mathrm{mab}$} \\
\hline 400 & 8457 & 30 & Nov. 12, 1991 & $1020, \mathrm{~A}$ & $22 \pm 7$ & & -21.73 \\
\hline 405 & 8480 & 30 & Dec. 12,1991 & $1020, \mathrm{~B}$ & $20 \pm 7$ & & -21.87 \\
\hline 408 & 8482 & 30 & March 11, 1992 & $1118,1 \mathrm{~A}$ & $89 \pm 9$ & & -22.07 \\
\hline 412 & 8506 & 30 & March 11, 1992 & 1118,1 & & $60 \pm 10$ & -21.05 \\
\hline 411 & 8507 & 30 & April 10, 1992 & $1118,2 B$ & $\ldots *$ & & -22.68 \\
\hline 413 & 8466 & 30 & April 10, 1992 & 1118,2 & & $27 \pm 8$ & -20.63 \\
\hline 409 & 8483 & 30 & May 10,1992 & $1118,3 \mathrm{C}$ & $63 \pm 9$ & & -21.94 \\
\hline 414 & 8508 & 30 & May 10,1992 & 1118,3 & & $76 \pm 7$ & -19.10 \\
\hline 410 & 8505 & 30 & June 9,1992 & $1118,4 \mathrm{D}$ & $22 \pm 7$ & & -22.00 \\
\hline 415 & 8525 & 30 & June 9, 1992 & 1118,4 & & $71 \pm 8$ & -19.96 \\
\hline \multicolumn{8}{|c|}{$600 \mathrm{mab}$} \\
\hline 377 & 8412 & 10 & June 20,1991 & $621, \# 12$ & $38 \pm 6$ & & -21.05 \\
\hline 383 & 8418 & 30 & July 10, 1991 & $728,1 \mathrm{A \#} 1$ & $57 \pm 10$ & & -21.72 \\
\hline 384 & 8419 & 30 & July 10,1991 & $728,1 \mathrm{~A} \# 2$ & $39 \pm 7$ & & -21.95 \\
\hline 385 & 8422 & 30 & July 10, 1991 & $728,1 \mathrm{A \#} 3$ & $40 \pm 7$ & & -21.93 \\
\hline 403 & 8524 & 30 & Nov. 12,1991 & $1020, \mathrm{~A}$ & $22 \pm 7$ & & -21.68 \\
\hline 396 & 8523 & 30 & Dec. 12,1991 & $1020, \mathrm{~B}$ & $45 \pm 8$ & & -21.39 \\
\hline 397 & 8429 & 30 & Jan. 11,1992 & $1020, \mathrm{C}$ & $76 \pm 7$ & & \\
\hline 398 & 8455 & 30 & Feb. 10, 1992 & $1020, \mathrm{D}$ & $99 \pm 8$ & & -21.94 \\
\hline \multicolumn{8}{|c|}{$100 \mathrm{mab}$} \\
\hline 381 & 8416 & 30 & March 12, 1991 & 621,1 & $34 \pm 8$ & & -21.83 \\
\hline 382 & 8417 & 30 & April 11, 1991 & 621,2 & $99 \pm 7$ & & -21.60 \\
\hline 380 & 8415 & 30 & June 10,1991 & 621,4 & $50 \pm 7$ & & -20.70 \\
\hline 389 & 8424 & 30 & July 10, 1991 & $725,1 \mathrm{~A}$ & $34 \pm 6$ & & -21.31 \\
\hline 388 & 8421 & 30 & Aug. 9, 1991 & $725,2 \mathrm{~B}$ & $121 \pm 12$ & & -21.75 \\
\hline 386 & 8420 & 30 & Sept. 8, 1991 & $725,3 \mathrm{C}$ & $110 \pm 8$ & & \\
\hline 387 & 8423 & 30 & Oct. 8,1991 & $725,4 \mathrm{D}$ & $154 \pm 7$ & & -22.94 \\
\hline 395 & 8428 & 30 & Nov. 12, 1991 & $1014,1 \mathrm{~A}$ & $5 \pm 7$ & & -21.80 \\
\hline 406 & 8481 & 30 & Dec. 12,1991 & $1014, \mathbf{B}$ & $-21 \pm 8$ & & -21.73 \\
\hline 399 & 8456 & 30 & Jan. 11, 1992 & $1014, \mathrm{C}$ & $41 \pm 9$ & & -21.78 \\
\hline 401 & 8479 & 30 & Feb. 10, 1992 & $1014,4 \mathrm{D}$ & $98 \pm 9$ & & -21.69 \\
\hline \multicolumn{8}{|c|}{$50 \mathrm{mab}$} \\
\hline 379 & 8414 & 10 & June 10,1991 & 621, \#11 & $50 \pm 9$ & & -20.90 \\
\hline 378 & 8413 & 10 & June 20,1991 & $621, \# 12$ & $38 \pm 7$ & & -20.81 \\
\hline 390 & 8426 & 10 & June 30,1991 & $725, \# 1$ & $54 \pm 7$ & & -21.34 \\
\hline 391 & 8425 & 10 & July 10,1991 & $725, \# 2$ & $87 \pm 7$ & & -21.87 \\
\hline
\end{tabular}

CAMS and UCID numbers are as described in Table 1 caption. Also listed are the trap collection duration, midpoint date for each collection, and cruise event and cup number. Three filter pads from a single cup deployment $(600 \mathrm{mab}$, event $728,1 \mathrm{~A})$ were run for $\Delta^{14} \mathrm{C}$, and the three values were within $2 \sigma$ error. The $\Delta^{14} \mathrm{C}$ and $\delta^{13} \mathrm{C}$ measurements of organisms (swimmers) picked out of the four trap cups recovered from 650 mab during the Pulse 12 cruise (June 1992) are also listed; dates of these collections are February 25 to March 26, March 26 to April 25, April 25 to May 25, and May 25 to June 24, 1992. The last cup $(1118,4)$ did not sequence shut before being retrieved through the water column during recovery; thus some POC and organisms could have been from depths shallower than 650 mab.

${ }^{*}$ A sample from the 650 -mab trap whose $\Delta^{14} \mathrm{C}$ value was $360 \%$, which indicated contamination with tracer levels of ${ }^{14} \mathrm{C}$.

levels of ${ }^{14} \mathrm{C}$, and the $\Delta^{14} \mathrm{C}$ value was not included in Figure 6a or Table 2. Because of numerous breaks in the isotope records from each depth, it is difficult to make unequivocal statements regarding trends in these data. However, several observations are noteworthy.

First, the $\Delta^{14} \mathrm{C}$ of $\mathrm{POC}_{\text {sink }}$ varied from a high value of $154 \%$ in October 1991 to a low value of $-21 \%$ in December 1991; both of these extreme values were from samples in the 100mab trap. The $\mathrm{POC}_{\text {sink }} \Delta^{14} \mathrm{C}$ values from trap material collected in June 1991 from 600 mab $(38 \pm 6 \%$ ) and $100 \mathrm{mab}$ $(50 \pm 7 \% 0)$ were within $2 \sigma$ error of the DIC $\Delta^{14} \mathrm{C}$ value available for $25 \mathrm{~m}$ depth in June 1991, $49 \pm 10 \%$ (P. M. Williams, unpublished data, 1991). The $\Delta^{14} \mathrm{C}$ value of $\mathrm{POC}_{\text {sınk }}$ from 100 mab in February $1992(98 \pm 9 \%$ ) was within $2 \sigma$ of one of the surface $(25 \mathrm{~m}) \mathrm{POC}_{\text {susp }} \Delta^{14} \mathrm{C}$ values found during February $1992\left(81 \pm 12 \%\right.$ o). There were no other surface $\Delta^{14} \mathrm{C}$ values of DIC or POC taken from February 91 to June 1992 for comparison with the $\mathrm{POC}_{\text {sink }}$ values. The three $\Delta^{14} \mathrm{C}$ values from the 100-mab trap from August, September, and October 1991 (110-154\%o) seemed high in comparison with the highest DIC $\Delta^{14} \mathrm{C}$ value obtained for surface waters at station $M$ taken over a 4-year period. Though we do not think that these three $\mathrm{POC}_{\text {sink }} \Delta^{14} \mathrm{C}$ analyses were contaminated with tracer ${ }^{14} \mathrm{C}$, this possibility could not be ruled out.

Second, there appeared to be two minima in $\mathrm{POC}_{\text {sink }} \Delta^{14} \mathrm{C}$ in 1991 and one in the middle of 1992. These periods coincided 
with maxima in deep sinking POC flux rates of greater than 5 $\mathrm{mg} \mathrm{C} \mathrm{m} \mathrm{m}^{-2} \mathrm{~d}^{-1}$ as measured at this site during May to June 1991 (30-day average flux rates at $50 \mathrm{mab}$ of $9.6-17.2 \mathrm{mg} \mathrm{C}$ $\mathrm{m}^{-2} \mathrm{~d}^{-1}$ ), October to mid-January 1992 (30-day average flux rates of 13.9-6.4 $\mathrm{mg} \mathrm{C} \mathrm{m}^{-2} \mathrm{~d}^{-1}$ ), and May to June 1992 [Smith et al., 1994; K. L. Smith, personal communication, 1995]. When the flux of organic carbon in these deep traps was plotted versus the $\Delta^{14} \mathrm{C}$ values of the $\mathrm{POC}_{\text {sink }}$ (Figure 6b) there was an apparent inverse correlation. The data representing the 650 and 600-mab traps were less scattered and had lower average $\Delta^{14} \mathrm{C}$ values than those from the deeper traps. This apparent correlation between high flux and low $\Delta^{14} \mathrm{C}$ was initially counterintuitive. We would have expected a higher $\Delta^{14} \mathrm{C}$ signature associated with the periods of high POC flux, indicative of a greater portion of surface-derived material arriving in the deep sea. Instead, we saw the opposite trend. This relationship between low $\Delta^{14} \mathrm{C}$ of $\mathrm{POC}_{\text {sink }}$ and high $\mathrm{POC}_{\text {sink }}$ flux rates are likely the result of increased communication between the sinking and suspended forms of POC (see discussion).

Third, the $\Delta^{14} \mathrm{C}$ values of the four $\mathrm{POC}_{\text {sink }}$ samples from 10-day deployments of the 50-mab trap during mid-1991 were not significantly different from those of the two 30-day samples collected at the same time in the 100-mab trap. This indicated that the relative amounts of surface-derived organic carbon (high $\Delta^{14} \mathrm{C}$ ) and resuspended organic carbon (low $\Delta^{14} \mathrm{C}$ ) present at the two near-bottom depths were similar during this time.

Fourth, $\mathrm{POC}_{\text {sink }} \Delta^{14} \mathrm{C}$ values from samples collected from 650 mab in March and June 1992 were $85 \%$ and $62 \%$ greater than the $\mathrm{POC}_{\text {susp }} \Delta^{14} \mathrm{C}$ values collected from 600 mab during February and June 1992 (Figure 6a). A similar observation was also reported from the north central Pacific (NCP) site $\left(31^{\circ} \mathrm{N}\right.$, $159^{\circ} \mathrm{W}$ ) in 1987 [Druffel et al., 1992], where $\mathrm{POC}_{\text {sink }} \Delta^{14} \mathrm{C}$ values were $86 \%$ and $81 \%$ higher than $\mathrm{POC}_{\text {susp }} \Delta^{14} \mathrm{C}$ from 600 and $1600 \mathrm{mab}$, respectively. This trend seemed logical, as $\mathrm{POC}_{\text {sink }}$ fell at a much faster rate than $\mathrm{POC}_{\text {susp }}$ and contained a greater proportion of labile organic compounds [Lee and Wakeham, 1988]. Presumably, these labile compounds reflected mostly a surface-derived source of carbon, high in ${ }^{14} \mathrm{C}$.

The $\Delta^{14} \mathrm{C}$ measurements of groups of small organisms (swimmers) picked from the 650-mab trap material were available for the four time periods March, April, May and June 1992 (Table 2). The organisms in all four traps were a mixture of two or three pteropods (Clio scheelei predominantly, 2-4

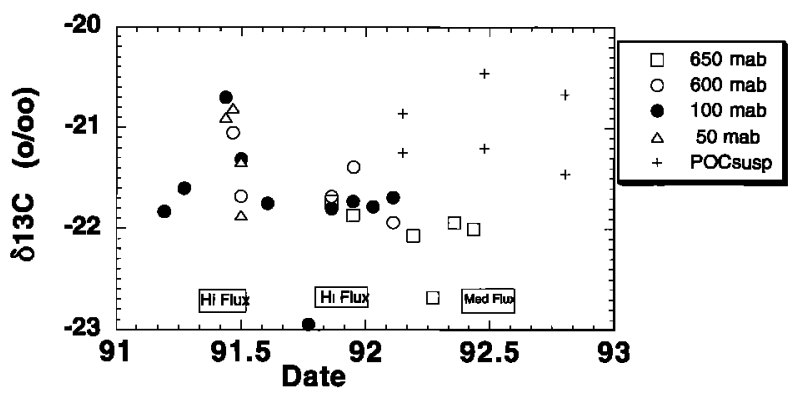

Figure 7. The $\delta^{13} \mathrm{C}$ of POC collected in sediment traps deployed at station $M$ at four depths: $650,600,100$, and 50 mab. All samples were collected over a 30-day period, with the exception of the 50 -mab samples, which were collected over 10 -day periods. For comparison, $\delta^{13} \mathrm{C}$ of $\mathrm{POC}_{\text {susp }}$ samples collected during three time periods at 50 and 650 mab are plotted as pluses.

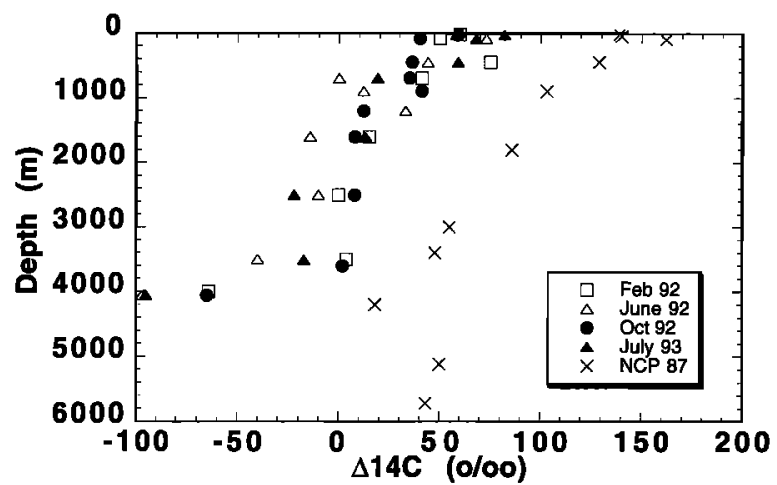

Figure 8. A comparison of the $\Delta^{14} \mathrm{C}$ measurements for $\mathrm{POC}_{\text {susp }}$ at station $\mathrm{M}$ (this work) and the north central Pacific (NCP) [Druffel et al., 1992] during 1992 to 1993 and 1987, respectively.

$\mathrm{mm}$ in length) and amphipods, and one copepod each in the March and June traps. Three of the four $\Delta^{14} \mathrm{C}$ values were as high as surface DIC $\Delta^{14} \mathrm{C}$ values $(72 \%$ at $25 \mathrm{~m}, 42 \%$ at $85 \mathrm{~m}$ ) and $\mathrm{POC}_{\text {susp }} \Delta^{14} \mathrm{C}$ values $(58 \%$ at $25 \mathrm{~m}, 73 \%$ at $85 \mathrm{~m}$ ) measured in samples from this site in June 1992. This agreement indicated that the carbon source to these organisms was mostly surface-derived POC. The April trap contained an amphipod that had about 100 small juveniles in its pouch. The reason for the low $\Delta^{14} \mathrm{C}$ value (27\%o) of this sample may be the result of a relatively large amount of $\mathrm{POC}_{\text {susp }}$ assimilated from depth (with low $\Delta^{14} \mathrm{C}$ values) during the amphipod's gestation of its young.

The $\delta^{13} \mathrm{C}$ signatures of the $\mathrm{POC}_{\text {sink }}$ are shown in Figure 7. All but five values fall within the range -21.0 to $-22.1 \%$. The three high outliers occur in the 100-mab and 50-mab traps during May-June 1991, a period of very high flux. The lowest value (100 mab, October 1991) is $-22.9 \%$; the accompanying $\Delta{ }^{14} \mathrm{C}$ value for this sample is the highest value obtained for any $\mathrm{POC}_{\text {sink }}$ sample. There is no simple correlation between the $\delta^{13} \mathrm{C}$ and $\Delta^{14} \mathrm{C}$ values for the $\mathrm{POC}_{\text {sink }}$ samples. Overall, $\mathrm{POC}_{\text {sink }}$ $\delta^{13} \mathrm{C}$ values are lower by $0.4-0.7 \%$ than the two $\mathrm{POC}_{\text {susp }} \delta^{13} \mathrm{C}$ values available for samples collected from $600 \mathrm{mab}$ at the same time (Pulse 11 and 12, see Table 1 and Figure 7).

\section{Discussion}

POC $_{\text {susp }} \Delta^{14} \mathrm{C}$ Gradient With Depth: Comparison With North Central Pacific Data

We observed a large gradient of $\mathrm{POC}_{\text {susp }} \Delta^{14} \mathrm{C}$ values (80$160 \%$ ) between surface and deep ocean $(3500 \mathrm{~m})$ from our four cruises. A similar gradient (100-130\%o) was observed in NCP samples collected during a single cruise in June-July 1987 (see Figure 8 ), where values were $+150 \%$ in the surface and 20-50\%o in the deep ocean [Druffel and Williams, 1990]. Higher surface values were obtained in the NCP because the samples were collected 5 years earlier when the bomb ${ }^{14} \mathrm{C}$ signal was higher overall in the temperate surface ocean [Druffel, 1987]. In addition, unlike the NCP, station M is located in the California Current, where upwelling brings low$\Delta^{14} \mathrm{C}$ waters from below the mixed layer up to the surface. Aside from the consistent offset of $80 \%$ between the two sites (excluding the 50-mab samples at station M), the NCP and station $\mathrm{MPOC}_{\text {susp }} \Delta^{14} \mathrm{C}$ records are similar in shape (Figure 8). 
The DOC $\Delta{ }^{14} \mathrm{C}$ data published separately from the NCP [Druffel and Williams, 1990] and station M (BDWWG) reveal a similar pattern. There is a consistent $40 \%$ offset between the DOC $\Delta^{14} \mathrm{C}$ profiles from the NCP site and the average station $M$ values, with the NCP profile having higher values. The offset toward lower values for both the POC $\mathrm{Pusp}_{\text {sp }}$ and DOC $\Delta^{14} \mathrm{C}$ at station $\mathrm{M}$ is likely due to the lowering of bomb $\Delta^{14} \mathrm{C}$ in the surface since the late 1970s [Druffel and Williams, 1991] and the upwelling of low $\Delta^{14} \mathrm{C}$ carbon to the surface. The smaller offset observed between the DOC $\Delta^{14} \mathrm{C}$ profiles (40\%) at NCP and station $\mathrm{M}$ than between the POC $\Delta^{14} \mathrm{C}$ profiles $(80 \%)$ ) is, in part, a function of the different turnover times for $\mathrm{POC}_{\text {susp }}$ and DOC in the water column. POC $_{\text {susp }}$ is recycled on a much faster timescale with the labile organic matter remineralized relatively quickly as compared with the refractory nature of most of the DOC.

\section{POC-DOC Association}

The real mystery of these isotope data lies in the very existence of the $\mathrm{POC}_{\text {susp }}$ (and to a lesser extent the $\mathrm{POC}_{\text {sink }}$ ) $\Delta^{14} \mathrm{C}$ gradient with depth. As was discussed in the introduction, a gradient should not be present if (1) the carbon source for

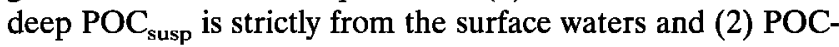
susp transits the water column on relatively short timescales (weeks to 10 years).

Indeed, the $\Delta^{14} \mathrm{C}$ measurement of $\mathrm{POC}_{\text {susp }}$ reported here do not support these assumptions but instead suggest another possibility. Could the $\Delta^{14} \mathrm{C}$ gradient with depth reflect a general aging of $\mathrm{POC}_{\text {susp }}$ with depth in the oceans? In order to obtain an average deep POC $\mathrm{POsp} \Delta^{14} \mathrm{C}$ value of $8 \%$ (average of 1600 and $2500 \mathrm{~m}$ values in February and October 92), we calculate that $36 \%$ of this deep carbon pool still has its prebomb $\Delta^{14} \mathrm{C}$ value of $-70 \%$ [Berger et al., 1966] and $64 \%$ has been replaced with postbomb $\mathrm{POC}_{\text {susp }}$ from the surface ocean (52\%o, average of 25 and $85 \mathrm{~m} \Delta^{14} \mathrm{C}$ POC $_{\text {susp }}$ measurements, February and October 92). This result would suggest that the turnover time of $\mathrm{POC}_{\text {susp }}$ in the deep ocean is several decades, instead of the value of 5-10 years obtained from Th isotope studies [Bacon and Anderson, 1982]. What does not fit this analysis is the seasonal change in the concentration of $\mathrm{POC}_{\text {susp }}$ at middepth, which shows that $70 \%$ of the $\mathrm{POC}_{\text {susp }}$ is removed in less than half a year (from October 1992 to February 93) (Figure 4 and E. R. M. Druffel, unpublished data from Pulse 16, February 1993). This agrees with Sherrell [1994; also manuscript in preparation, 1996], who finds that suspended mass concentration from 400 to $3600 \mathrm{~m}$ decreased by approximately a factor of 2 between June 1991 and February 1992 at station $\mathrm{M}$. It is not known where this $\mathrm{POC}_{\text {susp }}$ goes each year, though it may be stripped out of the water column by midwater grazers who produce marine snow and fecal pellets $\left(\mathrm{POC}_{\text {sink }}\right)$ that fall to the deep ocean. This $\mathrm{POC}_{\text {sink }} / \mathrm{POC}_{\text {susp }}$ association mechanism may cause the $\mathrm{POC}_{\text {sink }}$ to have low $\Delta^{14} \mathrm{C}$ signature during high flux periods. We cannot address the mechanism of this change in isotopic signature, but we can speak to the source of the low $-\Delta{ }^{14} \mathrm{C}$ carbon.

Another scenario deals with the fact that organic particles (POC) are suspended in a soup of relatively concentrated dissolved organic matter (DOC), and sorption of DOC by $\mathrm{POC}_{\text {susp }}$ or any particle is likely. Studies of the characteristic surface charge exhibited by solids in seawater have shown that dissolved organic matter quickly and irreversibly sorbs to particles [Hunter and Liss, 1982; Neihof and Loeb, 1973]. In the upper $25 \mathrm{~m}$ at station M, DOC concentrations ranged from 63 to $74 \mu M$ (BDWWG), a factor of 10-25 times higher than our POC $_{\text {susp }}$ concentrations (3-6 $\mu M$ ). In the deep water column at station M, DOC (37-41 $\mu M)$ is a factor of 90-400 times higher than $\mathrm{POC}_{\text {susp }}(0.1-0.4 \mu M)$. Mechanisms for the incorporation of DOC into the POC pool may include (1) abiotic incorporation by physical sorption of DOC on/into the particle, (2) biotic incorporation of DOC by heterotrophic bacteria associated with the particles, and (3) anapleurotic reactions in the deep ocean that incorporate old, deep DIC into the POC pool [Rau et al., 1986].

Estimates can be made of the amount of "old," sorbed DOC needed to decrease the $\Delta^{14} \mathrm{C}$ of the "modern" $\mathrm{POC}_{\text {susp }}$ to the observed average deepwater values for the four profiles. Assuming that DOC $\Delta^{14} \mathrm{C}$ is $-450 \%$ at $450 \mathrm{~m}$ and $-550 \%$ below $700 \mathrm{~m}$ (BDWWG) we calculate that $7 \%$ of the $\mathrm{POC}_{\text {susp }}$ at $450 \mathrm{~m}$ and $12 \%$ of the $\mathrm{POC}_{\text {susp }}$ at $3500 \mathrm{~m}$ would need to consist of DOC to obtain the observed average $\mathrm{POC}_{\text {susp }} \Delta^{14} \mathrm{C}$ values. This constitutes about $1 \%$ or less of the water column DOC inventory; hence, it would not be associated with a detectable seasonal depletion in the concentration of DOC due to the proposed "stripping out" of DOC and subsequent in-

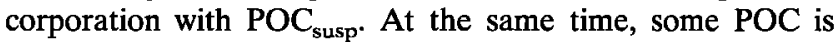
likely converted to DOC via dissolution or degradation (BDWWG) and contributes to the labile fraction of DOC in the water column.

The similarity of the $\Delta^{14} \mathrm{C} \mathrm{POC}$ susp profiles for February and October 1992 (Figure 3a), despite the factor-of-3 difference in $\mathrm{POC}_{\text {susp }}$ concentration between these two time periods (Figure 4), points to similar relative amounts of old DOC sorbed to young POC during both seasons. The incorporation of DOC onto suspended particulate matter is a plausible mechanism to explain the gradient of $\Delta^{14} \mathrm{C}$ in $\mathrm{POC}_{\text {susp }}$ observed during the seasons that were studied at our northeastern Pacific site.

Changes in DOC concentrations were observed at station $M$ by BDWWG. They observed that at all subsurface depths (except the oxygen minimum at $700 \mathrm{~m}$ ), DOC concentrations were lowest (by 5-7 $\mu M$ ) during periods of highest flux (>10 mg C $\mathrm{m}^{-2} \mathrm{~d}^{-1}$, June 1991 and July 1993). Consequently, DOC concentrations were highest during the extended low-flux ENSO period of 1992. Low $\mathrm{POC}_{\text {sink }} \Delta^{14} \mathrm{C}$ values found during periods of high flux (Figures 6a and 6b) appear to occur concomitantly with low DOC concentrations in the deep sea. These data indicate that DOC may be stripped out of the water column during periods of high POC flux, and sorbed onto particles. The $\delta^{13} \mathrm{C}$ values of $\mathrm{POC}_{\text {sink }}$ support this hypothesis, as the $\delta^{13} \mathrm{C}$ is highest (and closer to DOC $\delta^{13} \mathrm{C}$ values) during the high-flux period of June 1991. However, sorption of DOC onto particles could not account for the seasonal changes observed in DOC concentrations. If we assumed that a flux rate of $20 \mathrm{mg} \mathrm{C} \mathrm{m}^{-2}$ $\mathrm{d}^{-1}$ in the deep sea (1000-4000 m) was the only loss of DOC, it would take 25 years to reduce the DOC concentration from 43 to $38 \mu M$. Obviously, the $\mathrm{POC}_{\text {sink }}$ flux rate is too slow to account for the observed seasonal change in DOC concentration, just as the sorption of DOC onto $\mathrm{POC}_{\text {susp }}$ accounts for less than $1 \%$ of the available DOC. Instead, heterotrophic utilization of labile DOC that arrives seasonally to the deep sea is the likely cause of the observed seasonal DOC concentration changes.

The $\mathrm{POC}_{\text {susp }} \Delta^{14} \mathrm{C}$ data shows a small seasonal change of $\Delta^{14} \mathrm{C}$ (20-30\%o in June 1992 and July 1993) superimposed on a large depth gradient. $\mathrm{POC}_{\text {susp }}$ appears to be influenced less by changes in flux rates than the quickly falling, and much larger-sized $\mathrm{POC}_{\text {sink }}$ particles. Surprisingly, the concentration 
of $\mathrm{POC}_{\text {susp }}$ below $700 \mathrm{~m}$ varies by a factor of 3 from February to October 1992 (Figure 4). Given the relatively small seasonal variability of $\mathrm{POC}_{\text {susp }} \Delta^{14} \mathrm{C}$ values compared with the large depth gradient, the amount of DOC associated with $\mathrm{POC}_{\text {susp }}$ (and particulate matter in general) appears to vary directly with the $\mathrm{POC}_{\text {susp }}$ concentration. That is, the amount of DOC sorbed to $\mathrm{POC}_{\text {susp }}$ during October 1992 would have to be approximately 3 times greater than that sorbed during February 1992. This suggests a physicochemical control of the association between the DOC and $\mathrm{POC}_{\text {susp }}$ (or particulate matter), a process that would depend on the surface area that is available for sorption. The overall higher $\delta^{13} \mathrm{C}$ values observed for $\mathrm{POC}_{\text {susp }}$ than for $\mathrm{POC}_{\text {sink }}$ indicate a higher relative abundance of DOC in the $\mathrm{POC}_{\text {susp }}$ pool, which agrees with the lower $\Delta^{14} \mathrm{C}$ values observed in $\mathrm{POC}_{\text {susp. }}$

\section{Lateral Transport of POC Locally or From the Continental Slope to Station $\mathbf{M}$}

Smith et al. [1994] observed an increase in particle fluxes at $50 \mathrm{mab}$ over those at $600 \mathrm{mab}$ during the summers of 1990 and 1991 at station M. They assert that lateral advection of particulate material is likely at this site during summer because of its proximity to the continental shelf and slope and the Monterey deep-sea fan. The $\Delta^{14} \mathrm{C}$ data display seasonal changes in two ways: (1) the seasonal variability of $\mathrm{POC}_{\text {sink }} \Delta^{14} \mathrm{C}$ is higher in the deeper $(100 \mathrm{mab})$ trap material (Figures $6 \mathrm{a}$ and $6 \mathrm{~b})$, and (2) the overall $\Delta^{14} \mathrm{C}$ values of $\mathrm{POC}_{\text {susp }}$ in the 50 -mab samples are lower for all of the profiles (Figure $3 \mathrm{a}$ ). We estimate the $\Delta^{14} \mathrm{C}$ signature of the organic carbon transported from the surface sediments to 50 mab for each $\mathrm{POC}_{\text {susp }}$ profile, assuming that the baseline concentration of $\mathrm{POC}_{\text {susp }}$ is equal to that at 600 mab. For example, during February 1992, if 68\% (1.42 $\mu \mathrm{g} \mathrm{L}^{-1} / 2.08 \mu \mathrm{g} \mathrm{L}^{-1}$ ) of the $\mathrm{POC}_{\text {susp }}$ at $50 \mathrm{mab}$ had a $\Delta^{14} \mathrm{C}$ value of $4 \% o$ (the average value at $650 \mathrm{mab}$ ), then the remainder of $\mathrm{POC}_{\text {susp }}(32 \%)$ at 50 mab would have had a $\Delta^{14} \mathrm{C}$ of $-208 \% 0$ in order to balance the observed $\mathrm{POC}_{\text {susp }} \Delta^{14} \mathrm{C}$ of $-64 \%$ at $50 \mathrm{mab}$ (see Table 1). In this way, the $\Delta^{14} \mathrm{C}$ of the organic carbon resuspended from bottom sediments to $50 \mathrm{mab}$ during June 1992, October 1992, and June 1993 would have been $-120 \% o,-177 \%$, and $-173 \%$, respectively. These values are similar to that $(-232 \pm 20 \%$ ) measured for surface sedimentary organic carbon at station M [Bauer et al., 1995; BDWWG] and supports our hypothesis that most of the extra $\mathrm{POC}_{\text {susp }}$ found at $50 \mathrm{mab}$ is resuspended sediment.

We observed $20 \%$ lower $\Delta^{14} \mathrm{C}$ values for most deep POC $_{\text {susp }}$ samples during June 1992 and July 1993 than for other months of the year (February and October 1992), despite similar or lower values in the surface waters (Figure $3 \mathrm{~b}$ ). The lower $\mathrm{POC}_{\text {susp }} \Delta^{14} \mathrm{C}$ values may be due to lateral advection of low $\Delta{ }^{14} \mathrm{C}$ sedimentary organic carbon that had been resuspended locally or resuspended and transported from the continental slope to the abyssal plain via eddies. The presence of an anticyclonic eddy was reported off the coast of northern California during June-July 1988 by Washburn et al. [1993]. They observed a turbidity layer between 200 and $260 \mathrm{~m}$ depth and concluded that it was the result of advection of resuspended sediments from the continental shelf into the deep ocean. They estimated the cross-shelf sediment mass flux is of the order of $10^{6} \mathrm{~kg}$ sediment $/ \mathrm{d}^{-1}$ and is a dominant feature during summer, when other transport processes are weak.

For comparison, we estimate the amount of advected carbon that would have had to be added to the $\mathrm{POC}_{\text {susp }}$ pool at station $M$ during June 1992 and July 1993 to lower the $\Delta{ }^{14} C$ profiles.
The average offset below $700 \mathrm{~m}$ of $\mathrm{POC}_{\text {susp }} \Delta^{14} \mathrm{C}$ during the two early summer periods from that of February and October 1992 is $20 \pm 5 \%$ o. If we assume that the $\Delta^{14} \mathrm{C}$ of the advected POC from the shelf is equal to the surface SOC at station $M$ $\left(-232 \%\right.$ ) [Bauer et al., 1995], then about $10 \%$ of the $\mathrm{POC}_{\text {susp }}$ in early summer would need to have been derived from resuspended SOC to account for the 20\%o lowering of $\Delta^{14} \mathrm{C}$. This contribution of $10 \%$ to deep $\mathrm{POC}_{\text {susp }}$ concentration during early summer $\left(10 \%=0.2-0.4 \mu \mathrm{g} \mathrm{L}{ }^{-1}\right.$; see Figure 4$)$ is small compared with the seasonal range of $\mathrm{POC}_{\text {susp }}$ concentration and would not necessarily have been detected in the concentration data (Figure 4). However, our data do not allow us to distinguish between local resuspension and lateral transport of resuspended sediment from the continental shelf and slope. In any case, it seems unlikely that resuspended sediment from any location could be the cause of a $\Delta^{14} \mathrm{C}$ decrease for so large a portion of the water column. It is more likely that increased sorption of DOC is responsible for the $20 \%$ lowering of POC $_{\text {susp }}$ $\Delta^{14} \mathrm{C}$ in the middepth and deep water pools in early summer.

\section{ENSO Effect on POC $\Delta^{14} \mathrm{C}$}

April through August 1992 was a period of lower than normal flux to the deep sea at station M [Smith et al., 1994]. This period coincided with the ENSO event that was observed worldwide from 1991 to 1993 . This site experienced unseasonably warm sea surface temperatures and unusually low flux during 1992 (K. L. Smith, personal communication, 1995). Despite the presence of ENSO during 1992 at this site, the $\Delta^{14} \mathrm{C}$ of $\mathrm{POC}_{\text {susp }}$ was similar for the two profiles during June 1992 and July 1993. This points to factors other than ENSO as the cause for low POC susp $^{14} \mathrm{C}$ during early summer, the most likely factor being additional sorption (via stripping out of the water column) of DOC by POC during June-July.

\section{Future Studies}

The time series of carbon isotope results presented here in deep sinking POC and suspended POC, as well as DOC and DIC, are continuing at station $\mathrm{M}$. We are also pursuing isotope studies of detrital aggregates that have been observed on the seafloor at this site during and subsequent to periods of high flux [Smith et al., 1994]. If the seawater-sediment boundary is the likely remineralization site for most of the POC falling to the deep sea, then isotope studies of the detrital aggregates and sediment slurry will help reveal the turnover time of this fraction of the actively cycling carbon pool.

\section{Conclusions}

The large gradient of $\mathrm{POC}_{\text {susp }} \Delta{ }^{14} \mathrm{C}$ observed with depth can be explained by the incorporation of "old" DOC, in an amount equal to $7-12 \%$ of the standing stock of $\mathrm{POC}_{\text {susp. }}$. The lowest $\mathrm{POC}_{\text {susp }} \Delta^{14} \mathrm{C}$ values were observed in the water column during June 1992 and July 1993, and are likely the result of additional sorption (via "stripping out" of the water column) of $\mathrm{DOC}$ by $\mathrm{POC}_{\text {susp }}$ and particulate matter in general during high-flux periods. Laterally derived POC resuspended from the continental slope and shelf sediment with subsequent transport to the deep ocean site could also contribute to these lower $\Delta^{14} \mathrm{C}$ values, though it seems an unlikely mechanism for causing a consistent lowering of $\Delta^{14} \mathrm{C}$ in $\mathrm{POC}_{\text {susp }}$ over such a large depth range of the water column. Sinking POC has higher average $\Delta^{14} \mathrm{C}$ values than $\mathrm{POC}_{\text {susp }}$, indicating the faster transit time of this fraction of POC from the surface to the deep sea. 
$\mathrm{POC}_{\text {sink }}$ has low $\Delta^{14} \mathrm{C}$ values during periods of high flux, indicating that old DOC may be stripped out of the water column, directly or indirectly (by exchange between $\mathrm{POC}_{\text {sink }}$ and older $\mathrm{POC}_{\text {susp }}$ ). The seasonal variability of DIC $\Delta^{14} \mathrm{C}$ is too small to account for the observed temporal changes in deep POC $_{\text {susp }}$ or $\mathrm{POC}_{\text {sink }} \Delta^{14} \mathrm{C}$. Instead, sorption of DOC by POC, and particulate matter in general, during periods of high flux appears to dominate the POC $\Delta^{14} \mathrm{C}$ signal at this site.

\begin{abstract}
Acknowledgments. We are indebted to Michaele Kashgarian, John Southon, and their colleagues at the LLNL Center for AMS for their support with the AMS ${ }^{14} \mathrm{C}$ analyses for most of our samples. We thank Ann McNichol and colleagues for several AMS ${ }^{14} \mathrm{C}$ analyses conducted at the WHOI NOSAMS Facility. We thank Sue Trumbore and Shuhui Zheng for their help and advice and for the use of their graphite preparation line at UCI. We are grateful for the help and support of Ken Smith, Roberta Baldwin, Rob Glatts, and colleagues in the collection of sediment trap samples and for shared ship time. We thank Jennifer Cherrier, Gary Shultz, and Bob Wilson for help with seagoing activities. Thanks go to the captain and the crew of the R/V New Horizon for their cooperation and assistance. We thank Carrie Masiello for preparing the DIC samples for ${ }^{14} \mathrm{C}$ analysis and for graphite production of many of the samples. Thanks go to $\mathrm{C}$. Eben Franks for the $\delta^{13} \mathrm{C}$ measurements at WHOI and to Beth Gaza and Xuchen Wang for technical assistance at UCI. We thank George Jackson, Ken Smith, Rob Sherrell, and two anonymous reviewers for their helpful comments on this manuscript. We acknowledge the $\mathrm{Na}$ tional Science Foundation Chemical Oceanography Division for their continued support through grants OCE-9101183 and OCE-9396278 (to E.R.M.D.), OCE-9101540 (to J.E.B.) and OCE-9100181 (to P.M.W.).
\end{abstract}

\section{References}

Bacon, M. P., and R. F. Anderson, Distribution of thorium isotopes between dissolved and particulate forms in the deep sea, J. Geophys. Res., 87, 2045-2056, 1982.

Bauer, J., C. Reimers, E. Druffel, and P. Williams, Isotopic constrains on carbon exchange between deep ocean sediments and sea water Nature, 373, 686-689, 1995.

Berger, R., R. Taylor, and W. Libby, Radiocarbon content of marine shells from the California and Mexican west coast, Science, 153, 864-866, 1966.

Broecker, W. S., R. Gerard, M. Ewing, and B. Heezen, Natural radiocarbon in the Atlantic Ocean, J. Geophys. Res., 65, 2903-2931, 1960.

Bruland, K. W., R. P. Franks, W. M. Landing, and A. Soutar, A southern California inner basin sediment trap calibration, Earth Planet. Sci. Lett., 53, 400-408, 1981.

Deuser, W. G., Seasonal and interannual variations in deep-water particle fluxes in the Sargasso Sea and their relation to surface hydrography, Deep Sea Res., 33, 225-246, 1986.

Druffel, E. R. M., Bomb radiocarbon in the Pacific: Annual and seasonal timescale variations, J. Mar. Chem., 45, 667-698, 1987.

Druffel, E. M., and T. W. Linick, Radiocarbon in annual coral rings from Florida, Geophys. Res. Lett., 5, 913-916, 1978.

Druffel, E. R. M., and P. M. Williams, Identification of a deep source of particulate organic carbon using bomb ${ }^{14} \mathrm{C}$, Nature, 347, 172-174, 1990.

Druffel, E. R. M., and P. M. Williams, Radiocarbon in seawater and organisms from the Pacific coast of Baja California, Radiocarbon, 33(3), 291-296, 1991.

Druffel, E. R. M., P. M. Williams, J. E. Bauer, and J. Ertel, Cycling of dissolved and particulate organic matter in the open ocean, J. Geophys. Res., 97, 15,639-15,659, 1992.
Eglinton, T., L. I. Aluwihare, J. E. Bauer, E. R. M. Druffel, and A. P. McNichol, Preparative capillary gas chromatographic isolation of individual compounds from complex matrices for radiocarbon dating, Anal. Chem., 68, 904-912, 1996.

Hunter, K., and P. Liss, Organic matter and the surface charge of suspended particles in estuarine waters, Limnol. Oceanogr., 27, 322$335,1982$.

Lee, C., and S. G. Wakeham, Organic matter in seawater: Biogeochemical processes, in Chemical Oceanography, edited by J. P. Riley, pp. 1-51, Academic, San Diego, Calif., 1988.

McNichol, A. P., G. Jones, D. Hutton, and A. Gagnon, The rapid preparation of seawater $\mathrm{TCO}_{2}$ for radiocarbon analysis at the National Ocean Sciences AMS Facility, Radiocarbon, 36(2), 237-246, 1994.

Michaelsen, J., X. Zhang, and R. Smith, Variability of pigment biomass in the California Current system as determined by satellite imagery, 2, Temporal variability, J. Geophys. Res., 93, 10,883-10,896, 1988.

Neihof, R., and G. Loeb, Dissolved organic matter in seawater and the electric charge of immersed surfaces, J. Mar. Res., 32(1), 5-12, 1973.

Peláez, J., and J. McGowan, Phytoplankton pigment patterns in the California Current as determined by satellite, Limnol. Oceanogr., 31, 927-950, 1986.

Rau, G. H., D. M. Karl, and R. S. Carney, Does inorganic carbon assimilation cause ${ }^{14} \mathrm{C}$ depletion in deep-sea organisms?, Deep Sea Res., 33, 349-357, 1986.

Sherrell, R., Particulate trace metals in the northeast Pacific water column: Seasonally variable residence times and advective sources (abstract), Eos Trans. AGU, 73(3), Ocean Sci. Meet. suppl., 235, 1994.

Smith, K. L., R. S. Kaufmann, and R. J. Baldwin, Coupling of nearbottom pelagic and benthic processes at abyssal depths in the North Pacific Ocean, Limnol. Oceanogr., 39, 1101-1118, 1994.

Smith, R. C., X. Zhang, and J. Michaelsen, Variability of pigment biomass in the California Current system as determined by satellite imagery, J. Geophys. Res., 93, 10,863-10,882, 1988.

Stuiver, M., and H. A. Polach, Discussion: Reporting of ${ }^{14} \mathrm{C}$ data, Radiocarbon, 19(3), 355-363, 1977.

Vernonclark, R., E. Goldberg, and K. Bertine, Organic and inorganic characterization of marine colloids, Chem. Ecol., 11, 69-83, 1995.

Vogel, J., D. Nelson, and J. Southon, ${ }^{14} \mathrm{C}$ background levels in an accelerator mass spectrometry system, Radiocarbon, 29(3), 323-333, 1987.

Washburn, L., M. Swenson, J. Largier, P. Kosro, and S. Ramp, Crossshelf sediment transport by an anticyclonic eddy off northern California, Science, 261, 1560-1564, 1993.

Williams, P., and T. Linick, Cycling of organic carbon in the ocean: Use of naturally occurring radiocarbon as a long and short-term tracer, $L A E A$ Rep. SM-191-26, pp. 153-167, Int. At. Energy Agency, Vienna, 1975 .

Williams, P. M., A. F. Carlucci, and R. Olson, A deep profile of some biologically important properties in the central NCP gyre, Oceanol. Acta, 3(4), 471-476, 1980.

J. E. Bauer, School of Marine Sciences, College of William and Mary, Gloucester Point, VA 23062.

E. R. M. Druffel and S. Griffin, Department of Earth System Science, University of California, Irvine, CA92697-3100. (e-mail: edruffel@ uci.edu)

P. M. Williams and D. Wolgast, Scripps Institution of Oceanography, University of California, San Diego, La Jolla, CA 92093.

(Received June 23, 1995; revised May 24, 1996; accepted May 27, 1996.) 